\title{
28 Resarach Soure \\ Pyrolysis of Polyethylene Terephthalate Granules in Presence of Lewis Brønsted Acid Sites Catalysts
}

\section{Aref Shahi}

Petroleum University of Technology

Behrooz Roozbehani ( $\nabla$ roozbehani@put.ac.ir)

Petroleum University of Technology

Mojtaba Mirdrikvand

Universität Bremen: Universitat Bremen

\section{Research Article}

Keywords: Polyethylene Terephthalate, catalytic cracking, polymer, thermo gravimetric analysis

Posted Date: March 1st, 2021

DOI: https://doi.org/10.21203/rs.3.rs-157465/v1

License: (c) (1) This work is licensed under a Creative Commons Attribution 4.0 International License.

Read Full License 


\section{Abstract}

Among municipal polymer wastes, Polyethylene Terephthalate (PET) is a unique agent because of its widespread usage and broad range of gaseous products in its catalytic cracking process. Pyrolysis of polyethylene terephthalate (PET) in a semi-batch reactor was investigated using a Lewis Brønsted acid sites catalysts. Experiments were performed under isothermal condition to determine reaction kinetic parameters, product compositions, catalyst/PET mass ratio and temperature effect on the conversion. The products of reaction consist of gas, solid, and liquid phase with a maximum liquid product of $6 \%$ at $350{ }^{\circ} \mathrm{C}$. The optimal catalyst/PET mass ratio and temperature were determined. Additionally, the reaction order and activation energy for the reaction were detected.

\section{Introduction}

Primary, secondary (or mechanical), and tertiary (or chemical) recycling are the major approaches for plastic recycling. The plastic materials can be reused as second hand products or modified products in primary and secondary recycling methods (Scheirs 1998; Sorum et al. 2001; Öztürk and Güçlü 2004; Nikles and Farahat 2005; 2012). In contrast, in chemical recycling methods, plastic wastes are converted into their constituent monomers or basic hydrocarbon feedstock (Al-Salem et al. 2009; Sinha et al. 2010; Welle 2011). Among the chemical recycling approaches, catalytic cracking pyrolysis of waste plastics is one of the most applicable methods, during which plastics are heated in the absence of oxygen and broken down into gaseous hydrocarbons, gasoline, or diesel, i.e., fuels (Demirbas 2004; Scheirs and Kaminsky 2006; Karayannidis and Achilias 2007; Jankauskaite et al. 2008).

The plastic type alone affects the yield of the pyrolysis process, molecular weight distribution and the quality of liquid products gained in the catalytic degradation process of waste plastics (Kumar and Rao 2003). In our previous studies in clean technologies and environmental policy, we have reported catalytic degradation of single and mixed polymer granules such as polystyrene, high density and low density polyethylene mixtures, which include various types of urban waste plastic disposals (Roozbehani et al. 2014, 2015, 2016; Sakaki et al. 2014; Imani Moqadam et al. 2015). Among all materials discussed so far, Polyethylene Terephthalate (PET) is rather a unique agent. That is due to its widespread usage as plastic bottle as well its low liquid production and wide range of gas products in its catalytic pyrolysis (Ding et al. 1997; Achilias and Karayannidis 2004). So far, catalyticdegradation of PEThas been extensively studied by other researchers (Aguado and Serrano 1999; Chiu and Cheng 1999; Park et al. 1999, 2019; Sakata et al. 1999; Awaja and Pavel 2005; Saha and Ghoshal 2005; Bartolome et al. 2012; Santos et al. 2018). For instance, the impact of heating rate on non-isothermal degradation and kinetic parameters in an inert atmosphere was studied (Jenekhe et al. 1983; Sorum et al. 2001; D. Spaseska 2010; Niksiar et al. 2015). It was revealed that the activation energy and pre-exponential factor are extremely affected by the rate of heating while the reaction order remains constant (Niksiar et al. 2015). It was also shown while the thermal degradation is affected by the particle size, it is strongly influenced by temperature in a range of $400{ }^{\circ} \mathrm{C}$ and $500{ }^{\circ} \mathrm{C}$ (Kpere-daibo 2009). Copper (II) chloride is known as one of the most active agents among catalysts used in PET catalytic cracking reactions (Chiu and Cheng 1999; Faravelli et al. 2001). It 
reduces the carbonaceous residues and increases the percentage weight loss of PET 3.5 times in comparison to thermal degradation at similar reaction conditions. Taking the weight loss of catalyst in course of reaction into consideration, copper (II) chloride was considered to be an effectual catalyst (Awaja and Pavel 2005; Báez et al. 2013). While catalytic cracking of PET using copper (II) chloride yielded a shortened cracking time, showed a similar temperature influence on the polymer weight loss as compared to thermal degradation process with a optimal catalyst/ PET weight ratio of 0.1 (Villain et al. 1994; Gladden and Mitchell 2011). The maximum of weight loss was reported $90.8 \%$ and 80.5 in presence and absence of catalyst, respectively(Chiu and Cheng 1999).

Thermal degradation in a nitrogen atmosphere at $200-700{ }^{\circ} \mathrm{C}$ was examined in a tubular furnace under isothermal conditions by Dzie et al (Dzi囚cioł and Trzeszczyński 1998). The main volatile substances evolved from PET in the thermal degradation in a nitrogen atmosphere were $\mathrm{CO}, \mathrm{CO}_{2}$, acetaldehyde, acetophenone, aliphatic hydrocarbons $\left(C_{1}-C_{4}\right)$, and benzene (Dzi 『cioł and Trzeszczyński 2000). Within the temperature range $200-300^{\circ} \mathrm{C}$, only acetaldehyde and formaldehyde were detected and at higher temperatures, the mixtures of volatile decomposition products of PET became more complex. The concentrations of carbon oxides, aromatic and aliphatic hydrocarbons increases by increasing temperature, where the maximum yields of acetaldehyde and vinyl benzoate were observed at $600^{\circ} \mathrm{C}$ (Dzi囚cioł and Trzeszczyński 2000). In another work, kinetics of PET soft drink's bottles wastes was investigated in a dynamic condition and at various heating rates in nitrogen atmosphere (Villain et al. 1994). It was found that PET pyrolysis results in a 70 to $80 \%$ polymer weight loss in the temperature range of 107 to $242^{\circ} \mathrm{C}$. The $\mathrm{n}^{\text {th }}$ order model technique provided a more precise prediction of experimental data than previously applied techniques yielding an activation energy of 322.3 and $338.98 \mathrm{~kJ} / \mathrm{mole}$ for Coca-Cola and Pepsi samples, and the order of reaction by of 1.72 (Saha and Ghoshal 2005).

In this work the conversion of PET using a Lewis Brønsted acid sites catalyst is studied. Catalytic measurement was conducted to convert PET into lighter compounds followed by a kinetic model determined from the experimental data. Different conversion percentages were assessed in various temperatures on gas, liquid and waste productions. The effect of temperatures during reaction was also assessed. The other aim of this study is to estimate the reaction model of PET thermal catalytic cracking. Since a few detailed studies on the kinetics of PET pyrolysis by thermo-gravimetric (TG) analysis have been, this work present results by employing a kinetic model.

\section{Material And Method \\ 2.1. Catalyst}

The catalyst used in the measurements contains Lewis Brønsted acid sites to improve the catalytic activity and product selectivity in the catalytic degradation of PET. This is because the Brønsted acid sites act as proton addition and the Lewis acid sites are in charge of hydride abstraction. Thus, the polymer degradation occurs at lower temperatures compared to non-catalytic pyrolysis. The Lewis (electron acceptor) and Brønsted (proton donor) in the catalyst controls acidity due to its crystalline structure. The 
acid sites were generated by Al species in the catalyst consisting of silica and alumina. The ratio of silica to Alumina (Al/Si) in the catalyst powder has also significantly affects the cracking of polymer chains. High acid site density enhances the cracking reaction of hydrocarbons. Note that the activated acidic sites of the catalyst are sensitive to metal impurities in the feed.

The catalytic and isothermal decompositions were carried out for a mixture of PET in bottle grade. General characteristics of bottle grade were acquired for the samples. A maximum DEG content of 2.0 $\mathrm{Wt} . \%$ was reported. The melting point was around $250^{\circ} \mathrm{C}$, the water content of the samples was $0.3 \mathrm{Wt} . \%$ with a maximum carboxyl end group level of 32. The amount of acetaldehyde was also determined to be $1 \mathrm{ppm}$ at its highest level.

The catalyst consists of the following components: (a) zeolite (molecular sieve), (b) palatine, (c) activematrix component, (d) inactive-matrix component, and (e) binder. The last two properties regulate the activity by dilution of the active components and to obtain the desired particle strength and morphology. Some characteristics of the catalyst are reported in Table 1.

Table 1

The main properties of the catalyst used in the experiments.

\begin{tabular}{|l|llll|}
\hline \multicolumn{1}{|l|}{ Property } & Unit & Minimum & Maximum \\
\hline $\mathrm{Al}_{2} \mathrm{O}_{3}$ & wt. \% & 38.5 & 48.2 \\
\hline $\mathrm{Pt}$ & $\mathrm{wt} . \%$ & 0.001 & 0.001 \\
\hline total surface area & $\mathrm{m}^{2} / \mathrm{gr}$ & 38 & 42 \\
\hline Attrition Index & $\mathrm{wt.} \%$ & 1.5 & 5.3 \\
\hline
\end{tabular}

The catalytic degradation experiments were carried on the pure PET granules in a Pyrex reactor under isothermal conditions at a temperature range of $330^{\circ} \mathrm{C}$ to $430^{\circ} \mathrm{C}$ with a step-wise increment of $10{ }^{\circ} \mathrm{C}$ and with the catalyst fractions of $10-40 \%$ at atmospheric pressure. The scheme of the setup used in the measurements is shown in Fig. 1.

A semi-batch reactor and Thermo-gravimetric analysis (TGA) equipment was used to carry out polymer degradation reaction. TGA is implemented to determine the rate of degradation in catalytic and thermal processes and determine the relationship between samples mass and temperature. The air in the system was purged with an $\mathrm{N}_{2}$ stream before each startup. The catalytic experiments were conducted in two steps: first, different catalyst fractions were examined. Regardless of the rate of weight loss, the percentage of conversion was determined at each temperature, and second, the optimum catalyst fraction was determined. The product consists of three-phases (solid, liquid, and gas), in which a remarkable portion is in the gas phase. A condenser was used to cool the vapor product formed in the 
reactor. The presence of solid in the output caused a blockage in some experiments, especially when the reaction temperature is high. In addition, due to the presence of solids at the outlet of the setup, the quality of the liquid product was low and measurement of the weight loss versus time was difficult. Analysis of the gas product is important due to its component. As the catalytic degradation occurs at atmospheric pressure, collection and sampling of the products in the constant-volume balloon was on some occasions challenging. Therefore, gas collector and different-volume balloons were used to collect the gaseous product for further analyses.

\subsection{Gas chromatography analysis}

The products derived from the degradation of PET were analyzed to determine the main consisting components. The products were analyzed using a capillary column gas chromatography with flame ionization detection (GC/FID) ((50 m x $25 \mu \mathrm{m}$ ID, $0.5 \mu \mathrm{m}$ film of silica gel film, AGILENT, US 10420012, GC equipped with an HP-5 capillary column). Helium was supplied as carrier gas at the flow rate of $15.8 \mathrm{ml} / \mathrm{min}$. The injector's temperature was set to a temperature and pressure of $250^{\circ} \mathrm{C}$ and $10 \mathrm{psi}$, respectively. The capillary column separated the liquid components based on their volatility/boiling point. A specific mixture containing alkanes was used to calibrate and determine the retention time in the chromatogram in order to be split into intervals according to the boiling points of the normal alkanes of the calibration mixture. Species were quantitively determined by a standard method by reliable detection of relative retention time of the components in a gas chromatography/ mass spectrometry (GC/MS) device once a component.

\section{Result And Discussion}

The parameters that influenced the conversion are discussed in this section. First, the effect of catalyst/polymer mass ratio is described. Afterward, the effect of temperature on the catalytic cracking process is discussed (Sect. 3.1.2).

\subsection{Thermal and catalytic degradation analysis of PET}

The effect of catalyst weight fraction on the conversion was investigated at different temperatures. Catalyst weight fraction range of 10 to $50 \%$ was chosen with a stepwise increment of $10 \%$. The conversion rate yielded from the catalyst ratios are given for different temperatures in Table 2. It can be seen that by an increment in catalysis quantity the percentage of weight loss of the reactant decreases. Generally, there is no liquid product in the thermal degradation of PET in the previous studies. However, some differences were observed regarding the product distribution in the current study which is discussed in Sect. 3.3. The effect of catalyst weight fraction on the weight loss of polymer is given in Fig. 2. Generally, the increase in polymer/catalyst ratio leads to a higher yield of gaseous hydrocarbons and the formation of coke. 
Table 2

Effect of temperature and catalyst weight fraction on conversion.

\begin{tabular}{|lllllll|}
\hline Catalyst weight fraction & \multicolumn{5}{l|}{ Conversion (\%) } \\
\hline $\mathbf{1 0}$ & $\mathbf{3 3 0} \mathbf{\circ}^{\circ} \mathbf{C}$ & $\mathbf{3 5 0} 0^{\circ} \mathbf{C}$ & $\mathbf{3 7 0}{ }^{\circ} \mathbf{C}$ & $390^{\circ} \mathbf{C}$ & $\mathbf{4 1 0}{ }^{\circ} \mathbf{C}$ & $\mathbf{4 3 0}{ }^{\circ} \mathbf{C}$ \\
\hline $\mathbf{2 0}$ & 20 & 33 & 56 & 67 & 75 & 84 \\
\hline $\mathbf{3 0}$ & 17 & 29 & 53 & 64 & 69 & 82 \\
\hline $\mathbf{4 0}$ & 12 & 25 & 48 & 60 & 66 & 79 \\
\hline $\mathbf{5 0}$ & 10 & 19 & 43 & 58 & 63 & 77 \\
\hline
\end{tabular}

Increasing the catalyst percentage, the amount of coke increases, and the color of the solid product changes from yellow to a colorless mode. PET particles are surrounded by the catalyst, this causes a decrease in the amount of solid and liquid products, but the gas production was increased. The best conversion rate was achieved at a temperature of $430{ }^{\circ} \mathrm{C}$ with a catalyst/polymer ratio of 1:10.

\subsection{Temperature}

The lowest conversion rate was obtained at catalyst to polymer mass ratio of $40 \%$ and at $330{ }^{\circ} \mathrm{C}$ (see Fig. 3). At a catalyst/polymer ratio of $1: 10$, only $20 \mathrm{wt}$. \% of the sample was degraded at $330{ }^{\circ} \mathrm{C}$, but when the temperature raised to $430{ }^{\circ} \mathrm{C}$, the weight loss percentage increased to $84 \%$. The color of the carbonaceous solid residue tends to be darker, as temperature increased in various catalyst mass ratios.

By increasing temperature, the conversion increases at a certain catalyst loading. Thus, the reaction time was determined by the reaction temperature. Maximum PET weight loss occurred at the beginning of the reaction. According to Table 3 , the degradation time rapidly decreases at higher temperatures (about $45 \mathrm{~min}$ at $430^{\circ} \mathrm{C}$ ). This fact is illustrated in Fig. 4, where the weight loss is plotted versus total processing time.

Table 3

Effect of time on conversion rate (catalyst mass fraction of $10 \%)$.

\begin{tabular}{|lllllll|}
\hline Temperature $\left({ }^{\circ} \mathbf{C}\right)$ & $\mathbf{3 3 0}$ & $\mathbf{3 5 0}$ & $\mathbf{3 7 0}$ & $\mathbf{3 9 0}$ & $\mathbf{4 1 0}$ & $\mathbf{4 3 0}$ \\
\hline Time (min) & 193 & 150 & 95 & 85 & 54 & 45 \\
\hline Conversion (\%) & 20 & 33 & 56 & 67 & 75 & 84 \\
\hline
\end{tabular}

\subsection{Products yield}

The yield of liquid, gas, and solid products versus temperature in the range of $330-430{ }^{\circ} \mathrm{C}$ with step-wise increment of $20^{\circ} \mathrm{C}$ are given in Table 4 . The main hydrocarbon products of pyrolysis are the alkane gases 
such as methane, ethane, and higher concentrations of the alkenes and ethylene. Due to the breakage of the chemical bonds during the pyrolysis, more gaseous products and consequently more aliphatic gases such as $\mathrm{CH}_{4}, \mathrm{C}_{2} \mathrm{H}_{6}$, and $\mathrm{C}_{2} \mathrm{H}_{4}$ is formed as displayed in Fig. 5c. One of the notable findings in this work is the presence of a large volume of ethylene in the products which increases by increasing temperature. The presence of a large volume of ethylene in gas is another interesting aspect regarding the products. Additionally, unlike the other PET analyses in the literature, in which no formation of liquid products is reported, a slight amount of liquid at $330^{\circ} \mathrm{C}$ and $350^{\circ} \mathrm{C}$ was formed in this study. The maximum liquid in products was reported to be $6 \%$ at temperature of $350{ }^{\circ} \mathrm{C}$ and a catalyst to polymer ratio of $10 \%$.

In general, the decomposition of PET results in the production of solid and gas products. The solid products include a small amount of fine pale-yellow particles mostly consisting of benzoic acid and terephthalic acid were found at the outlet of the reactor and some carbonaceous residue in the reactor. The solid phase product increases by increasing temperature. The formation of the solid phase is due to the breakage of more molecular bonds in higher temperatures. The main component of this solid product was terephthalic acid (TPA). TPA degrades to benzene, carbon dioxide and benzoic acid at high temperatures. Figure $5 \mathrm{~b}$ illustrates the increment of solid product in higher temperatures. The main components of the solid product are terephthalic acid and benzoic acid. As shown in Figs. $5 \mathrm{~d}$ and $5 \mathrm{e}$, the yield of benzoic acid, carbon dioxides, and benzene increase as temperature rises.

Table 4

Product yield versus temperature.

\begin{tabular}{|llll|}
\hline Temperature $^{\circ} \mathrm{C}$ & Solid & Liquid & Gas \\
\hline 330 & 7 & 3 & 10 \\
\hline 350 & 10 & 6 & 16 \\
\hline 370 & 16 & 2 & 35 \\
\hline 390 & 20 & 0 & 46 \\
\hline 410 & 22 & 0 & 53 \\
\hline 430 & 23 & 0 & 61 \\
\hline
\end{tabular}

Terephthalate is the primary product of the pyrolysis of polyethylene. By an increase in temperature the ratio of gas to solid increases. At $350^{\circ} \mathrm{C}$, the ratio of gas to solid is 1.42 and at $430{ }^{\circ} \mathrm{C}$ is 2.65 . The volatile substances formed in the pyrolysis are given in Table 5 specifically. 
Table 5

Volatile products of the catalytic degradation of

PET.

\begin{tabular}{|llll|}
\hline Gas composition & $350^{\circ} \mathbf{C}$ & $370^{\circ} \mathbf{C}$ & $390^{\circ} \mathbf{C}$ \\
\hline $\mathrm{CO}$ & 0 & 1 & 4 \\
\hline $\mathrm{CO}_{2}$ & 10.5 & 13 & 16 \\
\hline $\mathrm{CH}_{4}$ & 10 & 10 & 13 \\
\hline $\mathrm{C}_{2} \mathrm{H}_{6}$ & 4.5 & 6 & 7.5 \\
\hline Benzoic acid & 18 & 17.5 & 15 \\
\hline $\mathrm{C}_{2} \mathrm{H}_{4}$ & 32 & 34 & 41 \\
\hline Benzene & 1 & 1 & 2 \\
\hline $\mathrm{C}_{2} \mathrm{H}_{4} \mathrm{O}$ & 2.5 & 1.5 & 0.5 \\
\hline Other & 21.5 & 16 & 1 \\
\hline
\end{tabular}

\subsection{Kinetic parameters}

It is known that the thermal and catalytic decomposition process of PET atmospheric pressure can be represented by the reaction scheme: $A_{1(\text { s) }} \rightarrow A_{2(\text { s or l) }} \rightarrow A_{3}(\mathbf{g})$, where $A_{1}$ is the solid polymer with the structure and $A_{2}$ mainly consists terephthalic acid and benzoic acid. Subsequently, the rapid production of low molecular weight volatile fragments with consequent weight loss is expected. The volatiles $\left(A_{3}\right)$ are mostly $\mathrm{COOH}, \mathrm{CO}, \mathrm{CO}_{2}, \mathrm{C}_{2} \mathrm{H}_{4}$, and $\mathrm{CH}_{4}$. Since few detailed studies on the kinetics of PET pyrolysis by thermo-gravimetric (TG) analysis have been reported throughout the literature, this work presents results of this investigation by employing kinetic model (Sorum et al. 2001; Sánchez-Jiménez et al. 2009; AlSalem and Lettieri 2010).

Isothermal thermo-gravimetric analysis (TGA) was used to investigates the mass change of a sample as a function of temperature or time because the reaction process can be followed over a wide temperature range. The kinetic of PET decomposition is considered heterogeneous as more than one phase during reaction exists. The rate of reaction of a heterogeneous reaction can be described as follow:

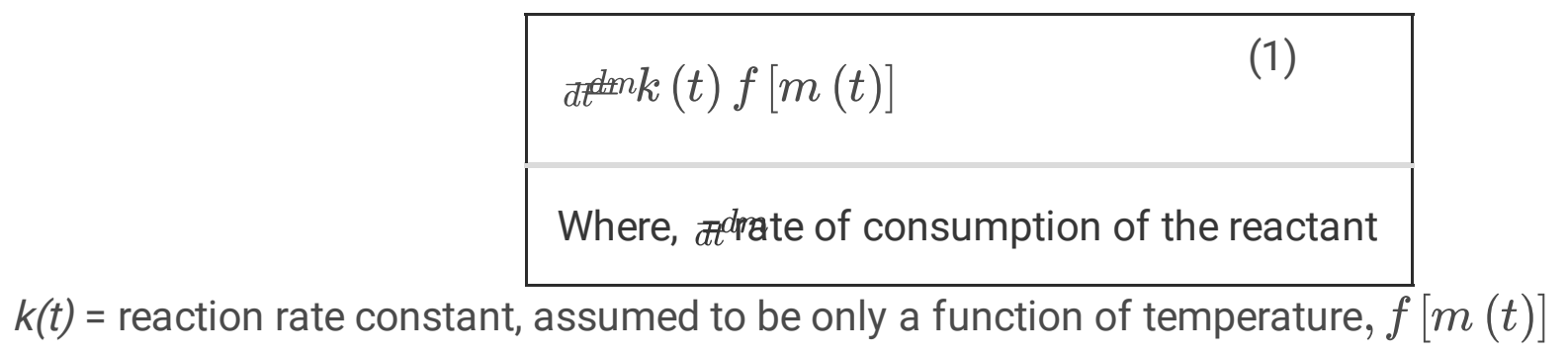


According to Eq. (1), for a heterogeneous system $k$ is usually defined using Arrhenius Law. Arrhenius Law is given as:

$$
k=A e^{(-E / R T)}
$$

Where $A$ is pre-exponential factor, $E$ is the activation energy $\left(\mathrm{kJ} \mathrm{mol}^{-1}\right), R$ represents the universal gas constant $\left(\mathrm{kJ} \mathrm{mol}^{-1} \mathrm{~K}^{-1}\right)$, and $T$ stands for temperature $(\mathrm{K})$.

$f[m(t)]$ has various forms depending upon the reaction system. The most commonly presumed form for the reaction is

$$
f[m(t)]=(m)^{n}
$$

where $n$ is the order of the reaction. By substituting equations (2) and (3) in Eq. (1), the general form of the kinetic equation is given as

$$
\operatorname{den} A e^{(-E / R T)}(m)^{n}
$$

Here, kinetic parameters in two modes were calculated $(n \neq 1$ and $n=1)$. According to Eq. (4), for each temperature a specific $n, E$, and $A$ exists. There are three unknowns parameters, so determination of the order of reaction $(\mathrm{n})$, for all temperature is possible. In addition, kinetic parameters change with temperature. For determination of $E$ and $A$ should be plotted $\operatorname{Ln}(k)$ versus $(1 / T)$. Logarithmic model of Eq. (4) is as follows:

$$
\ln (d) d \ln \left[\ln (A)-\frac{1}{2}+1+n \ln (m)\right.
$$

The values of the order of reaction for other temperatures $\left(330^{\circ} \mathrm{C}, 350^{\circ} \mathrm{C}, 390^{\circ} \mathrm{C}\right.$, and $410{ }^{\circ} \mathrm{C}$ ) are calculated by $n^{\text {th }}$ order kinetic model in Table 6 .

Table 6

Kinetics parameters derived for other temperatures.

\begin{tabular}{|ll|}
\hline Temperature (K) & $\mathbf{n}$ \\
\hline 603 & 1.04 \\
623 & 1.27 \\
643 & 1.49 \\
663 & 1.01 \\
683 & 1.49 \\
\hline
\end{tabular}

Page $9 / 18$ 


\subsubsection{Kinetic parameters (second mode, $n=1$ )}

we consider the order of the reaction equal to be one. Thus, Eq. (4) can be rewritten as follow when $n=1$ :

$$
d t^{m} A e^{(-E / R T)} m \quad(6)
$$

Manipulating this equation leads to

$$
\ln ({ })_{0}=-k\left(t-t_{0}\right)
$$

The $\mathrm{n}^{\text {th }}$ order model technique $n \neq 1$, yields a higher values of $E$ and $\operatorname{Ln}(A)$ compared to "first order" (see Table 7). Kinetic parameters change with temperature in different manner, even though one can assume that they are constant.

Table 7

Kinetics parameters derived from

experiments.

\begin{tabular}{|lll|}
\hline State & $\mathbf{E}\left(\mathrm{kJ} . \mathrm{mol}^{-1}\right)$ & $\mathbf{A}\left(\mathbf{m i n}^{-1}\right)$ \\
\hline$n=1$ & 323.87 & $48 \times 10^{21}$ \\
$n \neq 1$ & 109 & 1013141.08 \\
\hline
\end{tabular}

In case of $n \neq 1^{n}$ th order model technique, values of $E$ and $A$ are $109\left(\mathrm{~kJ} \mathrm{~mol}^{-1}\right)$, and $1013141.08\left(\mathrm{~min}^{-}\right.$ $\left.{ }^{1}\right)$ respectively. In this study, order of reaction changed from 1.01 to 1.49. Also, in "first order" technique $E$ and $A$ are reported to be $323.87\left(\mathrm{~kJ} \mathrm{~mol}^{-1}\right)$ and $48 \times 10^{21}\left(\mathrm{~min}^{-1}\right)$ respectively. Considering $n^{\text {th }}$ order model technique, it was found that when $n \neq 1$ is more suitable to describe the catalytic pyrolysis of the PET as no assumption or reaction degree is required unlike the first order technique.

\section{Conclusion}

The results showed the effect of temperature and catalyst/PET on the PET degradation using Lewis Brønsted acid sites catalyst. Increasing temperature reaction increased the conversion rate, where the products of the reaction form gas, liquid, and solid phases in contrary to other polymers that the product of the degradation mostly consist of liquid, less gas and no solid. The efficiency of degradation process decreased with increasing catalyst/PET mass ratio, since at higher catalyst ratios, the PET molecules surrounded by catalyst leading to lower reaction speed and insufficient heat transfer to PET molecules. 
The analysis of gas sample at higher temperature showed that $\mathrm{CO}, \mathrm{CO}_{2}$ and aliphatic hydrocarbons increased and terephthalic acid degraded to benzene and benzoic acid.

\section{Declarations}

\section{Conflicts of interest/Competing interests: NO}

Funding: Research Center of Chemical Engineering, Petroleum University of Technology, Abadan, Iran

Consent for publication/participate: All authors agree on publishing the results

Authors' contributions: All the authors are fully aware of their contribution in this research work. They have read, edited the final version of the manuscript submitted to CTEP.

Code availability: NO

\section{References}

Achilias DS, Karayannidis GP(2004) The chemical recycling of PETin the framework of sustainable development.Water, Air, Soil Pollut Focus. https://doi.org/10.1023/B:WAFO.0000044812.47185.0f

AguadoJ,Serrano D (1999) Feedstock Recycling of Plastic Wastes

Al-Salem SM, Lettieri P(2010) Kinetics of polyethylene terephthalate (PET) and polystyrene (PS) dynamic pyrolysis. World Acad Sci Eng Technol

Al-Salem SM, Lettieri P, Baeyens J (2009) Recycling and recovery routes of plastic solid waste (PSW): A review. Waste Manag.

Awaja F, Pavel D (2005) Recycling of PET. Eur. Polym. J.

Báez EV, Anguiano MGS, Pérez VMJ, et al (2013) Degradation of poly(ethylene terephthalate) waste with dimethyl tin distanoxane as a catalyst. J Appl Polym Sci. https://doi.org/10.1002/app.39361

Bartolome L, Imran M, Gyoo B, et al (2012) Recent Developments in the Chemical Recycling of PET. In: Material Recycling - Trends and Perspectives

Chiu SJ, Cheng WH (1999) Thermal degradation and catalytic cracking of poly(ethylene terephthalate). Polym Degrad Stab. https://doi.org/10.1016/S0141-3910(98)00121-9

D. Spaseska MC (2010) Nalkaline Hydrolysis of Poly(Ethylene Terephthalate) Recycled From the Postconsumer Soft-Drink Bottles. D Spaseska, M Civkaroska 379 J Univ Chem Technol Metall

Demirbas A (2004) Pyrolysis of municipal plastic wastes for recovery of gasoline-range hydrocarbons. J Anal Appl Pyrolysis. https://doi.org/10.1016/j.jaap.2004.03.001 
Ding W, Liang J, Anderson LL (1997) Thermal and catalytic degradation of high density polyethylene and commingled post-consumer plastic waste. Fuel Process Technol. https://doi.org/10.1016/S03783820(96)01080-6

Dzi囚cioł M, Trzeszczyński J (1998) Studies of temperature influence on volatile thermal degradation products of poly(ethylene terephthalate). J Appl Polym Sci. https://doi.org/10.1002/(sici)10974628(19980919)69:12<2377::aid-app9>3.0.co;2-5

Dzi囚cioł M, Trzeszczyński J (2000) Volatile products of poly(ethylene terephthalate) thermal degradation in nitrogen atmosphere. J Appl Polym Sci. https://doi.org/10.1002/10974628(20000829)77:9<1894::AID-APP5>3.0.CO;2-Y

Faravelli T, Pinciroli M, Pisano F, et al (2001) Thermal degradation of polystyrene. J Anal Appl Pyrolysis. https://doi.org/10.1016/S0165-2370(00)00159-5

Gladden LF, Mitchell J (2011) Measuring adsorption, diffusion and flow in chemical engineering: Applications of magnetic resonance to porous media. New J Phys 13:035001. https://doi.org/10.1088/1367-2630/13/3/035001

Imani Moqadam S, Mirdrikvand M, Roozbehani B, et al (2015) Polystyrene pyrolysis using silica-alumina catalyst in fluidized bed reactor.Clean Technol Environ Policy17:. https://doi.org/10.1007/s10098-0150899-8

JankauskaiteV, Macijauskas G, Lygaitis R (2008) Polyethylene terephthalate waste recycling and application possibilities: A review. Medziagotyra

Jenekhe SA, Lin JW, Sun B (1983) Kinetics of the thermal degradation of polyethylene terephthalate. Thermochim Acta. https://doi.org/10.1016/0040-6031(83)80283-4

Karayannidis GP, AchiliasDS (2007) Chemical recycling of poly(ethylene terephthalate). Macromol Mater Eng. https://doi.org/10.1002/mame.200600341

Kpere-daibo TS (2009) Plastic Catalytic Degradation Study of the role of external catalytic surface, Catalytic Reusability and Temperature Effects. Chem Eng

Kumar A, Rao TR (2003) Kinetics of hydrolysis of polyethylene terephthalate pellets in nitric acid. J Appl Polym Sci. https://doi.org/10.1002/app.11579

Lee SY, Yoon JH, Kim JR, Park DW(2001) Catalytic degradation of polystyrene over natural clinoptilolite zeolite. Polym Degrad Stab. https://doi.org/10.1016/S0141-3910(01)00162-8

Nikles DE, Farahat MS (2005) New motivation for the depolymerization products derived from poly(ethylene terephthalate) (PET) waste: A review. Macromol. Mater. Eng. 
Niksiar A, Faramarzi AH, Sohrabi M (2015) Kinetic study of polyethylene terephthalate (PET) pyrolysis in a spouted bed reactor. J Anal Appl Pyrolysis. https://doi.org/10.1016/j.jaap.2015.03.002

Öztürk Y, Güçlü G(2004) Unsaturated polyester resins obtained from glycolysis products of waste PET. Polym - Plast Technol Eng. https://doi.org/10.1081/PPT-200030272

Park DW, Hwang EY, Kim JR, et al (1999) Catalytic degradation of polyethylene over solid acid catalysts. Polym Degrad Stab. https://doi.org/10.1016/S0141-3910(99)00004-X

Park KB, Jeong YS, Guzelciftci B, Kim JS (2019) Characteristics of a new type continuous two-stage pyrolysis of waste polyethylene. Energy. https://doi.org/10.1016/j.energy.2018.10.078

Roozbehani B, Anvaripour B, Esfahan ZM, et al (2014) Effect of temperature and catalyst loading on product yield in catalytic cracking of high density polyethylene(hdpe).Chem Technol Fuels Oils 49:. https://doi.org/10.1007/s10553-014-0477-5

Roozbehani B, Motevassel M, Mirdrikvand M, et al (2016) Gasoline production from a polymeric urban disposal mixture using silica-alumina catalyst. Clean Technol Environ Policy. https://doi.org/10.1007/s10098-016-1196-x

Roozbehani B, Sakaki SA, Shishesaz M, et al (2015) Taguchi method approach on catalytic degradation of polyethylene and polypropylene into gasoline. Clean Technol Environ Policy 17:1873-1882. https://doi.org/10.1007/s10098-015-0901-5

Saha B, Ghoshal AK (2005) Thermal degradation kinetics of poly(ethylene terephthalate) from waste soft drinks bottles. Chem Eng J. https://doi.org/10.1016/j.cej.2005.04.018

Sakaki SA, Roozbehani B, Shishesaz M, Abdollahkhani N (2014) Catalytic degradation of the mixed polyethylene and polypropylene into middle distillate products. Clean Technol Environ Policy 16:901910. https://doi.org/10.1007/s10098-013-0688-1

Sakata Y, Uddin MA, Muto A (1999) Degradation of polyethylene and polypropylene into fuel oil by using solid acid and non-acid catalysts. J Anal Appl Pyrolysis. https://doi.org/10.1016/S0165-2370(99)000133

Sánchez-Jiménez PE, Pérez-Maqueda LA, Perejón A, Criado JM (2009) Combined kinetic analysis of thermal degradation of polymeric materials under any thermal pathway. Polym Degrad Stab. https://doi.org/10.1016/j.polymdegradstab.2009.07.006

Santos BPS, Almeida D, Marques M de F V., Henriques CA (2018) Petrochemical feedstock from pyrolysis of waste polyethylene and polypropylene using different catalysts. Fuel. https://doi.org/10.1016/j.fuel.2017.11.104

Scheirs J (1998) Polymer recycling: Science, Technology and Applications 
Scheirs J, Kaminsky W (2006) FeedstockRecycling and Pyrolysis of Waste Plastics: Converting Waste Plastics into Diesel and Other Fuels

Schneider D, Kondrashova D, Valiullin R, Bunde A (2015) Mesopore-Promoted Transport in Microporous Materials. 1794-1809. https://doi.org/10.1002/cite.201500037

Sinha V, Patel MR, PatelJ V. (2010) Pet waste management by chemical recycling: A review. J. Polym. Environ.

Sorum L, Gronli MG, Hustad JE (2001) Pyrolysis characteristics and kinetics of municipal solid wastes. Fuel. https://doi.org/10.1016/S0016-2361(00)00218-0

Villain F, Coudane J, Vert M(1994) Thermal degradation of poly(ethylene terephthalate) and the estimation of volatile degradation products. Polym Degrad Stab. https://doi.org/10.1016/01413910(94)90016-7

Welle F (2011) Twenty years of PET bottle to bottle recycling - An overview. Resour. Conserv. Recycl. (2012) Material Recycling - Trends and Perspectives

\section{Figures}

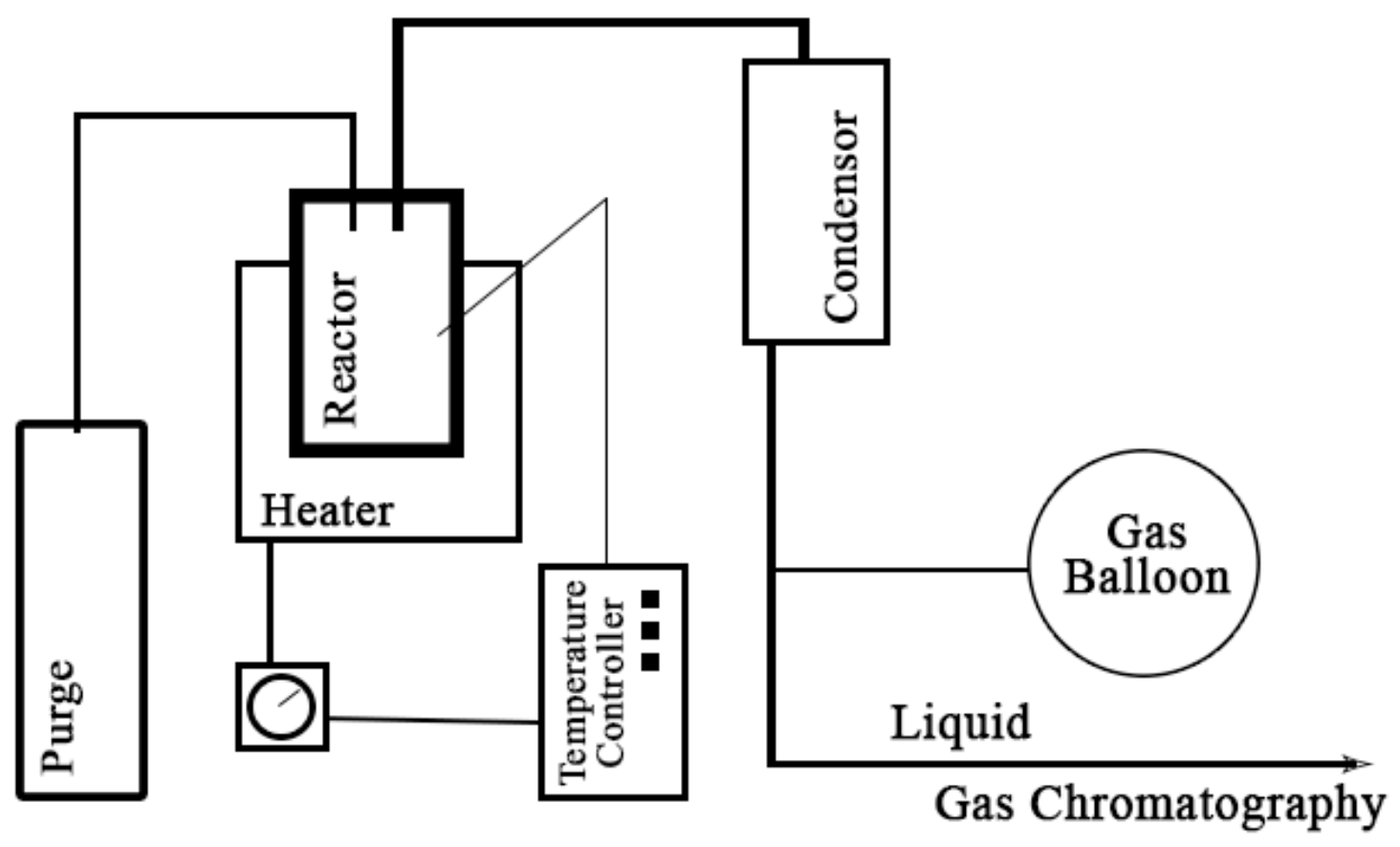

Figure 1

Scheme of apparatus used for the thermal and catalytic degradation studies of materials in a nitrogen atmosphere. 


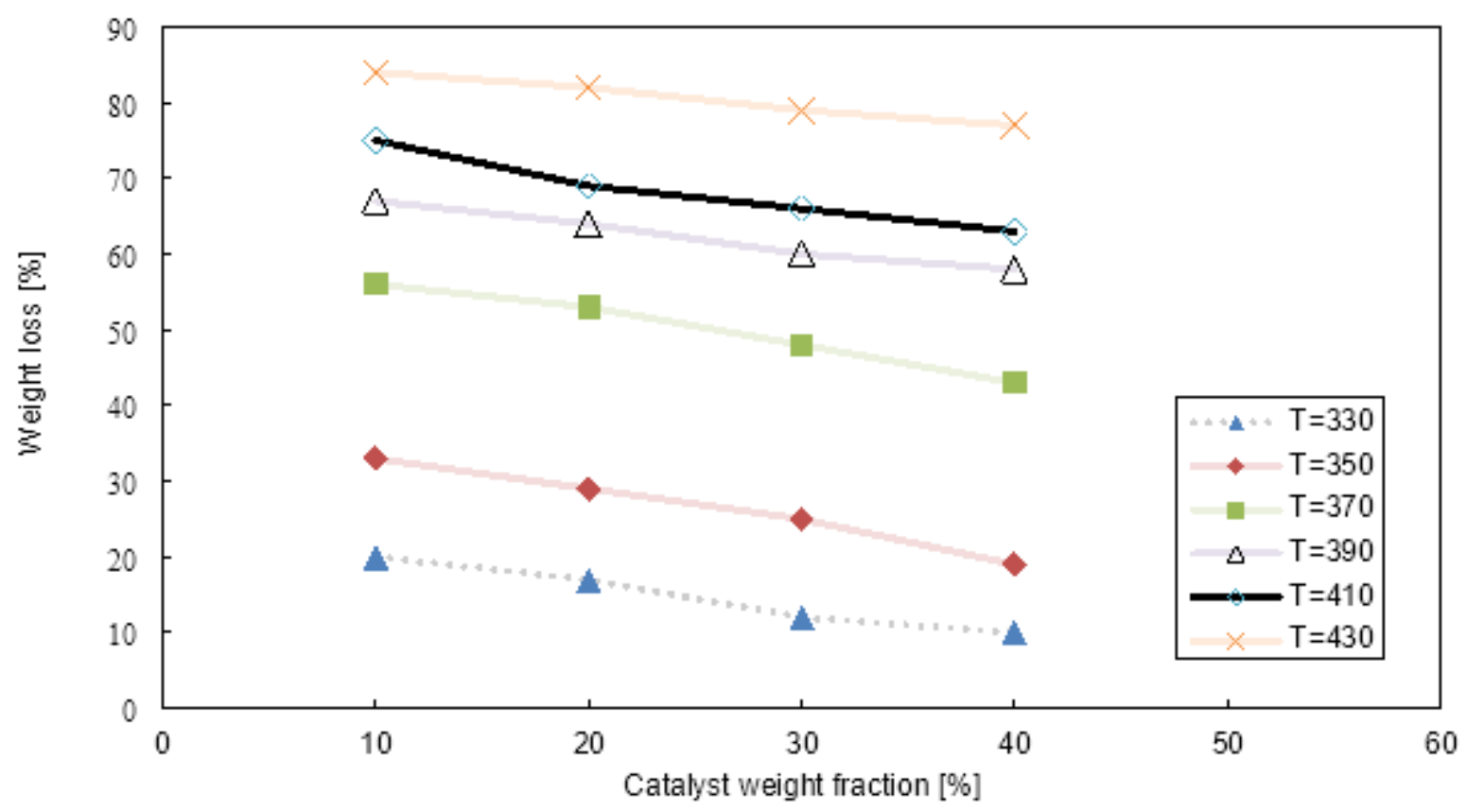

Figure 2

The catalyst weight fraction effect on the conversion.

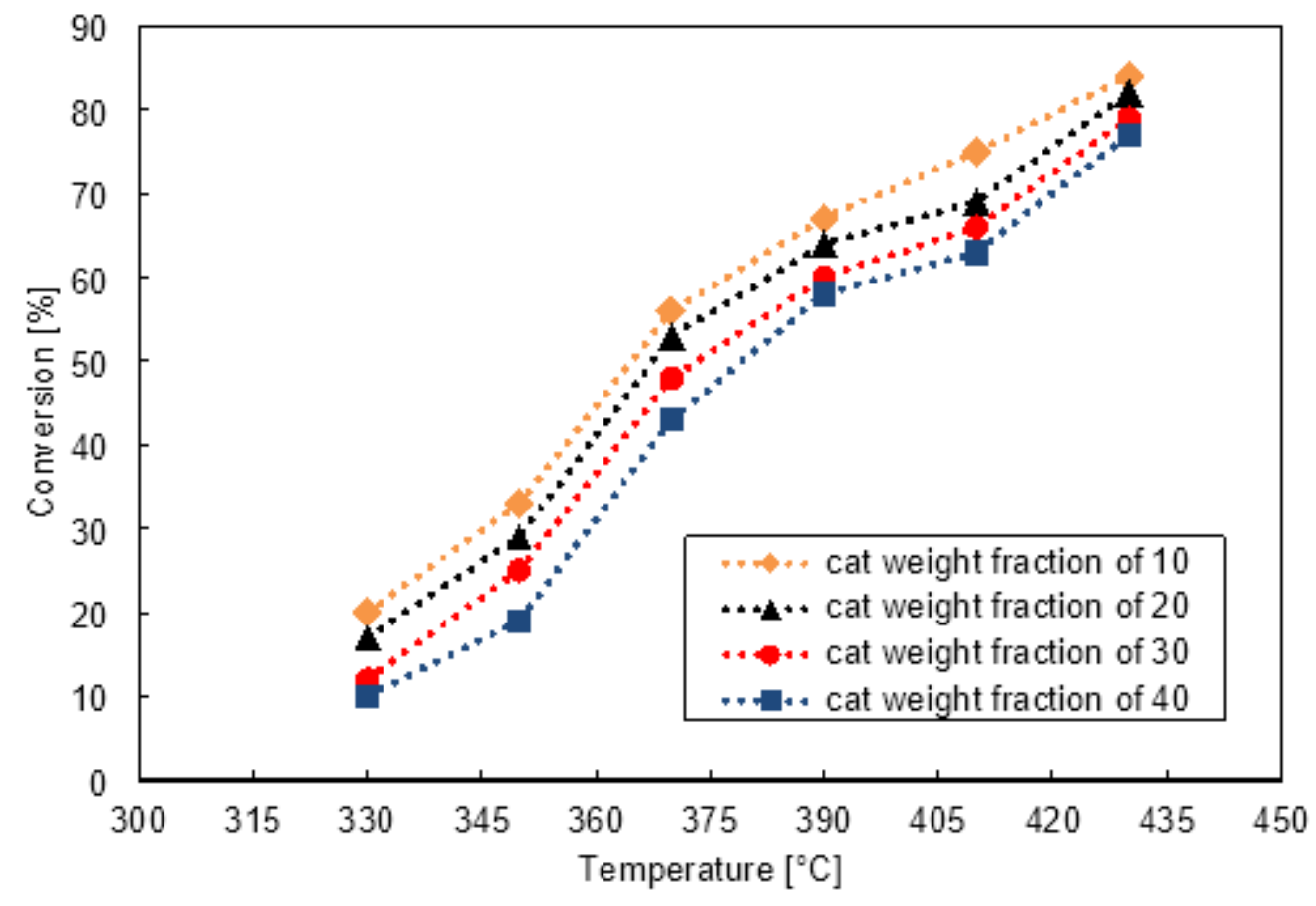

Figure 3

Effect of temperature on conversion rate in different catalyst weight fractions. 


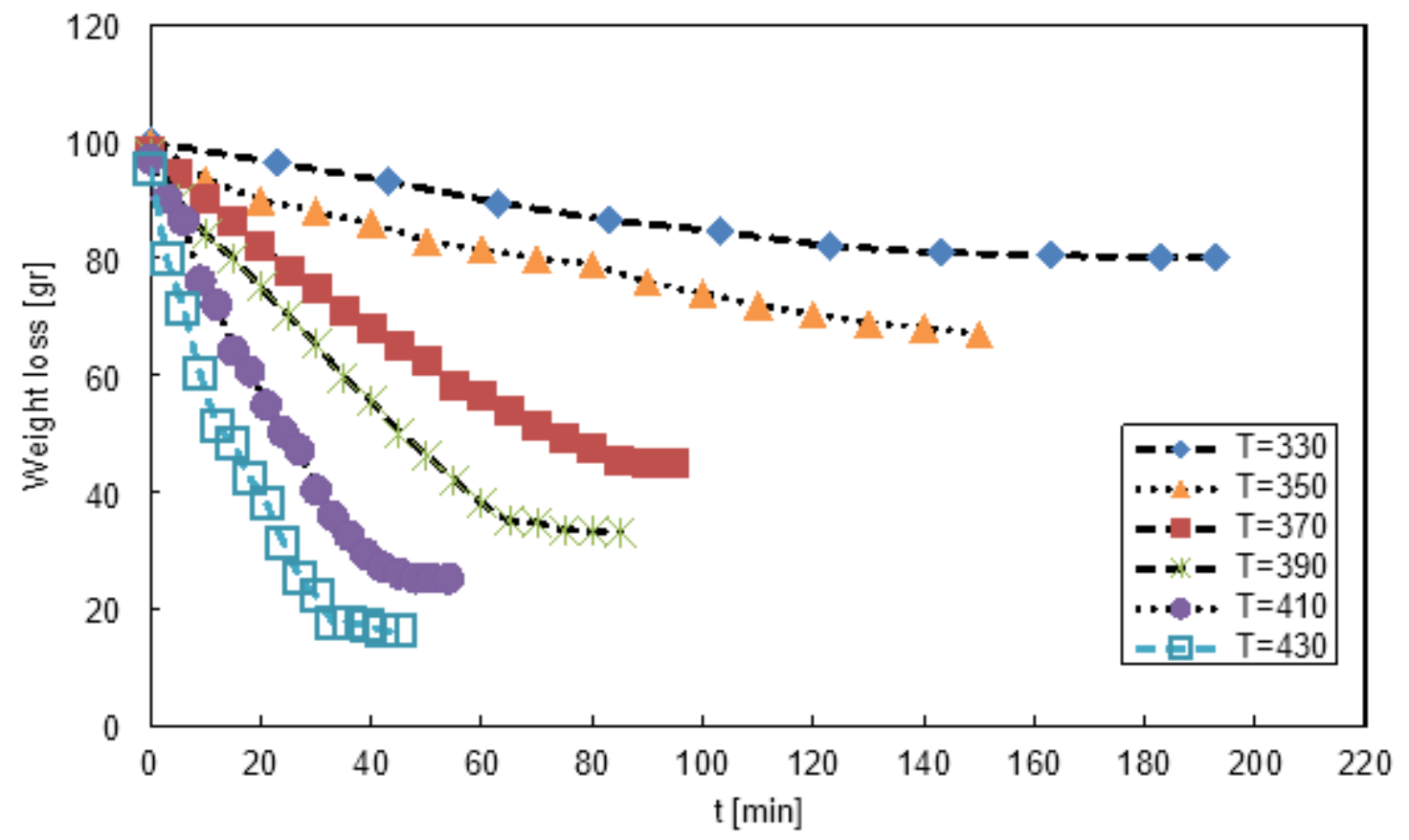

Figure 4

Weight loss of PET at different temperatures. 
(a)

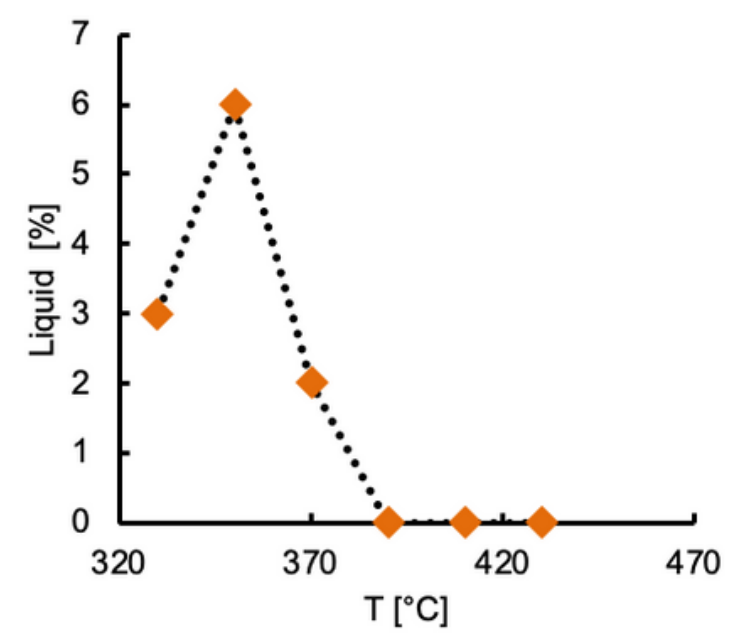

(c)

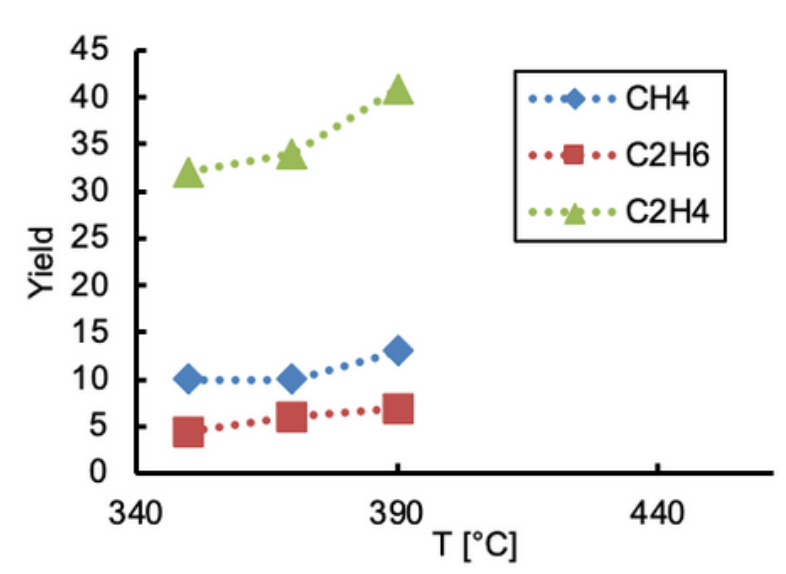

(e)

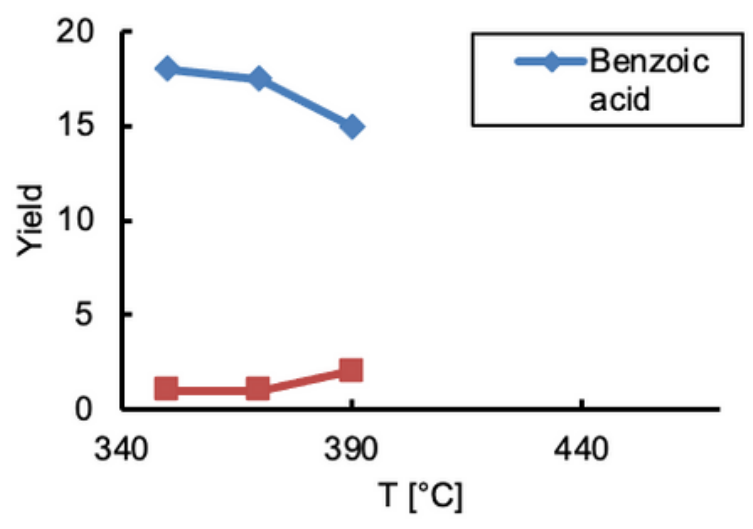

(b)

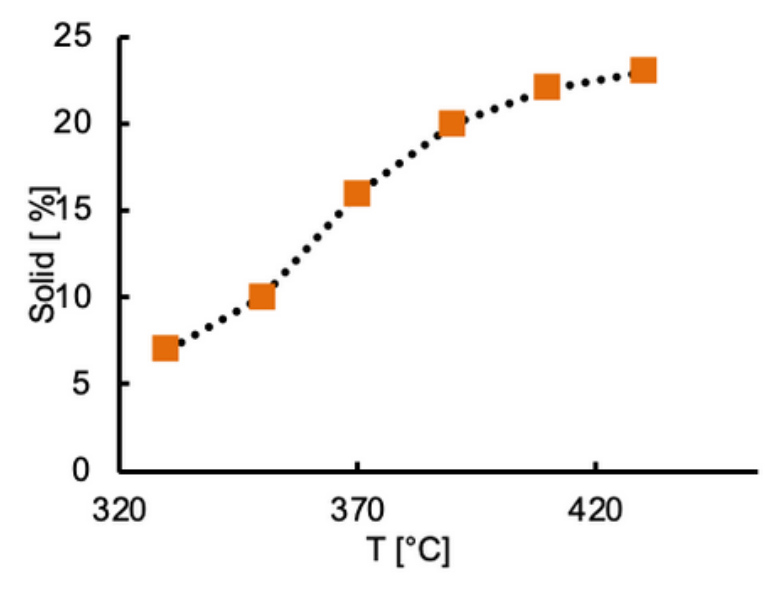

(d)

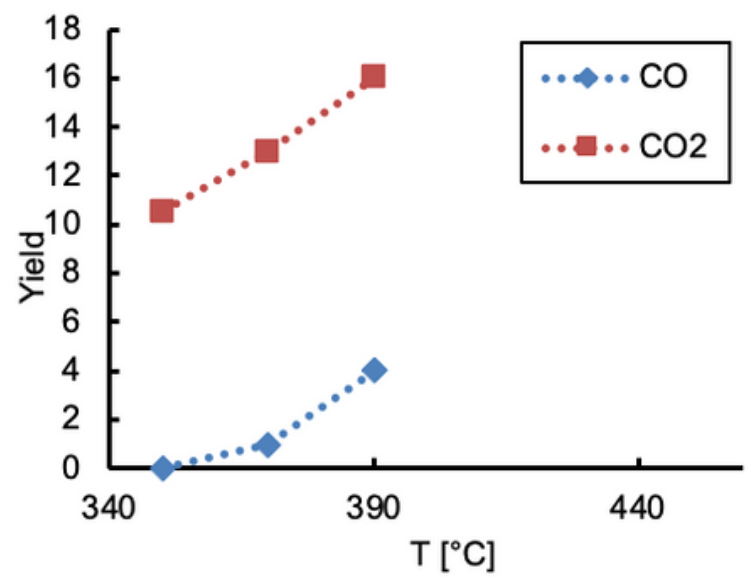

\section{Figure 5}

(a) Yield of liquid product, (b) solid product, (c) aliphatic gases, (d) aromatic gases, and (e) carbon oxides at various temperatures.

\section{Supplementary Files}


This is a list of supplementary files associated with this preprint. Click to download.

- graphical.tiff 